\title{
Desenvolvimento e caracterização de biocompósitos de polihidroxibutirato e fibra de bananeira
}

\author{
Development and Characterization of \\ Polyhydroxybutyrate and Banana Fiber \\ biocomposites
} Tatiana Barreto Rocha Nery ${ }^{1}$, Zora Ionara Gama dos Santos ${ }^{2}$,
Nádia Mamede José

\footnotetext{
${ }^{1}$ Centro Universitário SENAI CIMATEC - CEP 41650-010, Salvador, Bahia, Brasil.

${ }^{2}$ Departamento de Ciência e Engenharia de Materiais - Universidade Federal de Sergipe, CEP 49100-000, Aracajú, Sergipe, Brasil.

${ }_{3}^{3}$ Departamento de Físico-Química - Universidade Federal da Bahia - CEP 40170-115, Salvador, Bahia, Brasil. e-mail: tatiana.nery.br@gmail.com,nadiamamede@yahoo.com.br; zora.ufs@gmail.com
}

\section{RESUMO}

O PHB (Poli-3-hidroxibutirato) é um termoplástico biodegradável sintetizado por fermentação submersa a partir de matérias-primas renováveis. É um poliéster composto por elastômeros e termoplásticos lineares, cujas propriedades são de grande interesse científico e tecnológico, é um polímero altamente cristalino muito rígido e frágil, com propriedades de barreira e resistência química à hidrólise. O PHB puro tem seu processamento industrial restrito devido às suas propriedades físicas. Estudos têm demonstrado que a utilização de fibras naturais como reforço tem sido uma alternativa para redução do custo de produção e melhoria das propriedades térmicas e mecânicas de materiais poliméricos. A fibra da bananeira tem sido estudada como reforço polimérico, podendo tornar-se uma alternativa promissora, pois apresenta grande oferta, baixo custo, baixa densidade, baixa abrasividade, não-tóxico, renovável e totalmente biodegradável. O objetivo deste trabalho foi o estudo das propriedades mecânicas (resistência à tração), térmicas (Análise termogravimétrica, TGA, e Calorimetria Exploratória Diferencial, DSC), morfológicas e do Índice de Fluidez do PHB e de compósitos de PHB/fibra de bananeira (FB). As fibras foram tratadas quimicamente para mudança da superfície de contato. Foram preparados compósitos com concentrações de PHB/FB 90/05 e 90/10 (m/m). Os materiais foram processados por extrusão e moldados em prensa hidráulica para confecção dos corpos de prova. A incorporação da fibra causou alteração nos resultados mecânicos do material. Os melhores resultados foram alcançados com a mistura 90/05 (m/m).

Palavras-chave: Polihidroxibutirato, fibra de bananeira, tratamento alcalino, biocompósitos

\begin{abstract}
PHB (Poly-3-hydroxybutyrate) is a biodegradable thermoplastic polymer synthesized by fermentation from renewable materials. It is a polyester composed of elastomers and linear thermoplastics, whose properties are of great scientific and technological interest, is a very rigid and fragile polymer and highly crystalline with barrier properties and chemical resistance to hydrolysis. PHB has industrial processing restricted due to its physical properties. Studies have shown that the use of natural fibers as reinforcement has been an alternative for reducing the cost of production and improving the thermal and mechanical properties of polymeric materials. The banana fiber has been studied as a polymeric reinforcement, and can become a promising alternative, for being highly available, low density, low abrasiveness, non-toxic, and be renewable and biodegradable. The objective of this work was the study of the mechanical properties (tensile strength), thermal properties (thermogravimetric analysis, TGA, and Differential Exploratory Calorimetry, DSC), morphological and fluidity Index of PHB and PHB/banana fiber composites. The fibers were chemically treated to change the contact surface. PHB/FB composites with concentrations of 90/05 and 90/10 (m/m) were prepared. The materials were processed by extrusion and molded in a hydraulic press to make the specimens. The incorporation of the fiber caused a change in the mechanical results of the material. The best results were achieved with the
\end{abstract}


90/05 (m/m).

Keywords: Polyhydroxybutyrate; banana fiber; alkali treatment, biocomposites.

\section{INTRODUÇÃO}

O polihidroxibutirato - PHB, é um dos polihidrixialconoatos mais estudados e preferencialmente produzidos pela indústria, é um polímero oticamente ativo do $\mathrm{D}(-) 3$ - ácido hidroxibutírico (Figura 1a). Bactérias como a Alcaligenes eutrophus, produzem até $90 \%$ do seu peso seco de PHB (Figura 1b), com cristalinidade superior a $80 \%$ e massa molar em torno de $400.000 \mathrm{gmol}^{-1}$, com ponto de fusão de aproximadamente $178{ }^{\circ} \mathrm{C}[1,2]$.<smiles>COC(=O)CC(C)OC</smiles>

Mero [R]-hidroxibutirato<smiles>CCCCC(C)OCC</smiles>

Mero [S]-hidroxibutirato

(a) Fonte PACHEKOSKI, [3]

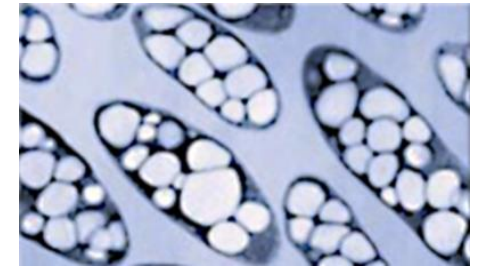

(b) Fonte SILVA et al., [4]

Figura 1: a) Estrutura química do PHB; b) Armazenamento de PHB por bactérias.

Uma das aplicações do polihidroxibutirato é como substituto biodegradável de polímeros olefinicos em embalagens (frascos, tampas, rótulos) e componentes estruturais. O PHB pode também ser utilizado internamente em seres humanos uma vez que estes polímeros são não-tóxico e compatíveis com tecidos vivos. Aplicações promissoras deste biomaterial na medicina são em: cápsulas gelatinosas para a ingestão de medicamentos, pinos, fios de sutura, enxertos ósseos, escovas cirúrgicas, tecidos cirúrgicos e como talco de lubrificação para luvas cirúrgicas [5,6].

As propriedades mecânicas do PHB são semelhantes as do polipropileno (PP), porém, apesar de possuir uma boa cristalinidade, o polihidroxibutirato é rígido e frágil, o que torna o seu uso limitado [3,7]. Como alternativa para melhoria das características de processo, tem-se estudado a mistura do PHB com outros polímeros (não necessariamente biodegradáveis) ou com fibras naturais. A utilização das fibras naturais como reforço para plásticos vem aumentando significativamente nas últimas décadas devido a fatores como o alto preço das fibras sintéticas e a busca crescente por materiais de baixo custo, provenientes de fontes renováveis de matérias-primas que não causem danos ao meio ambiente e que possam competir com os materiais tradicionais $[8,9]$.

A fibra de bananeira, extraída do pseudocaule da bananeira, tem sido estudada como reforço polimérico, podendo tornar-se uma alternativa promissora. Apresenta como vantagem o baixo custo, baixa densidade, fonte abundante, menor abrasividade, não tóxicas, rápida renovação e totalmente biodegradável. Algumas das características gerais são fibras longas e amareladas, branqueadas facilmente, sedosas, brilhantes, resistentes, elásticas, com diâmetros entre 2 a $8 \mathrm{~nm}$ [10]. O caráter polar das fibras vegetais dificulta a compatibilidade entre estas e as matrizes poliméricas que são geralmente de caráter hidrofóbico (apolar). Esta incompatibilidade dificulta a interação reforço/matriz, tendendo à formação de agregados durante o processamento, o que impacta diretamente nas propriedades mecânicas dos compósitos [9,10]. Este problema pode ser minimizado com o tratamento superficial da fibra ou com o uso de agentes de acoplagem. Quanto maior a adesão interfacial, melhor o desempenho do compósito, ou seja, mais efetiva é a transferência dos esforços da matriz para o reforço, aumentando o efeito reforçador das fibras.

O objetivo deste trabalho foi realizar a extração e tratamento químico da fibra de bananeira, aplicação da fibra como reforço a matriz PHB, e o estudo das propriedades mecânicas e térmicas do compósito PHB/fibra de bananeira (FB), a fim de avaliar a processabilidade e características mecânicas deste material, como possibilidade de um material comercialmente aplicável. 


\section{MATERIAIS E MÉTODOS}

\subsection{Material}

Para este trabalho foi utilizado o Polihidroxibutirato (PHB), na forma de pó, de nome comercial Biocycle fornecido pela PHB Industrial S.A e a fibra de bananeira da variedade prata, coletada no centro-oeste do estado da Bahia.

\subsection{Preparação da fibra}

A fibra de bananeira foi obtida pelo processo de desfibrilação do pseudocaule. A fibra extraída foi lavada em água corrente para retirada de excessos orgânicos e secadas ao sol por um período de 48 h. Foi realizado o tratamento alcalino das fibras com $\mathrm{NaOH}$ a $5 \%(\mathrm{~m} / \mathrm{v})$, em temperatura ambiente, por um período de $1 \mathrm{~h}$. Em seguida, as fibras foram lavadas com água até pH 7,0. Após essa etapa, as fibras foram secadas em estufa a $100{ }^{\circ} \mathrm{C}$ por $48 \mathrm{~h}$. As fibras foram cortadas no tamanho de $5 \mathrm{~mm}$ com o uso do Moinho de rolos da marca COPÉ mod.MAC 350 (Figura 2).

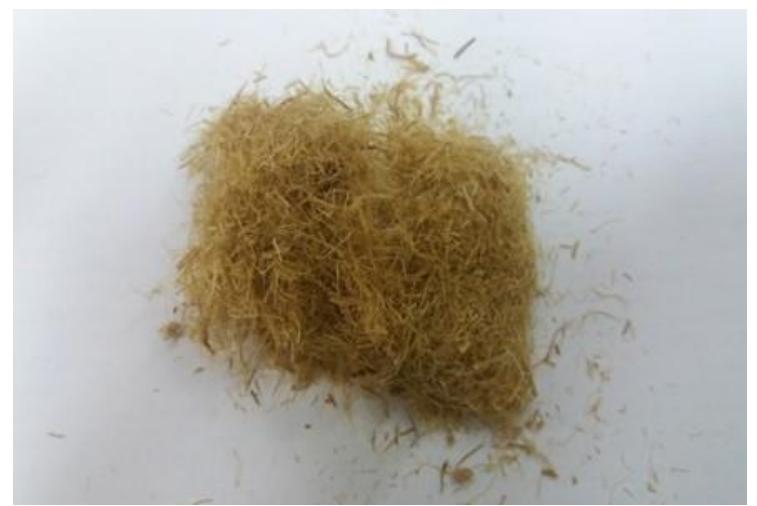

Figura 2: Fibra de bananeira triturada em moinho

\subsection{Preparação do compósito PHB/Fibra de Bananeira}

A fibra de bananeira e o PHB foram submetidos a uma secagem em estufa por 12 horas a $60{ }^{\circ} \mathrm{C}$, para eliminação da umidade absorvida. Esta prática objetivou evitar possíveis reações de desesterificação (hidrólise) durante o processamento bem como a formação de bolhas que comprometem as propriedades mecânicas e o acabamento do moldado.

Devido às condições limitadas de processamento, a etapa de extrusão do material foi realizada com controle rigoroso de temperatura e velocidade de processamento. Antes do processo de extrusão, polímero e fibra, na foram misturados manualmente, nas proporções de $5 \%$ e $10 \%$ de fibra de bananeira, de forma que o compósito tivesse praticamente sempre a mesma concentração de fibras distribuídas. Os componentes foram homogeneizados em extrusora dupla rosca co-rotacional da marca Imacon, modelo DRC 30:40 IF com diâmetro de rosca de $30 \mathrm{~mm}$ e razão $\mathrm{L} / \mathrm{D}$ de 40 . Os materiais de estudo foram processados com velocidade da rosca igual a 120 RPM, em forma de filetes, a uma temperatura de fusão de $160{ }^{\circ} \mathrm{C}$, e posteriormente resfriados com água a uma temperatura média de $30{ }^{\circ} \mathrm{C}$, com o objetivo de reduzir o gradiente de temperatura. 1,21 Após a etapa de extrusão, o material foi submetido ao processo de granulação e formação de pellets. $\mathrm{O}$ material foi levado à prensa hidráulica pré-aquecida a aproximadamente $160^{\circ} \mathrm{C}$, posicionado e mantido por aproximadamente $4 \mathrm{~min}$ em pressão de aproximadamente $3 \mathrm{MPa}$. Para retirada das placas os moldes foram resfriados com água em temperatura ambiente. Foram utilizados moldes vazados confeccionado em aço inox, para preparação dos corpos de prova.

\subsection{Caracterização do material}

O comportamento termogravimétrico dos materiais foi analisado numa termobalança Marca Shimadzu, Modelo TGA-50, de $22{ }^{\circ} \mathrm{C}$ a $1000{ }^{\circ} \mathrm{C}$, a uma taxa de aquecimento de $20{ }^{\circ} \mathrm{C} \mathrm{min}{ }^{-1}$, sob fluxo de nitrogênio. Para as análises de Calorimetria Exploratoria Diferencial (DSC), foi utilizado o equipamento da marca Shimadzu, modelo DSC-60, todas as amostras foram analisada entre $25{ }^{\circ} \mathrm{C}$ e $600{ }^{\circ} \mathrm{C}$, com taxa de aquecimento de $20{ }^{\circ} \mathrm{C}$ $\min ^{-1}$. O ensaio de tração foi realizado em máquina universal de ensaios EMIC DL 2000 seguindo norma ISO 527. O ensaio de impacto IZOD foi realizado numa máquina EMIC, modelo AIC 1, com martelo de 2,7 J seguindo a norma ISO 180. O ensaio de flexão foi realizado pela máquina EMIC DL 2000 seguindo norma 
ISO 178. O ensaio de dureza SHORE D, indicado para materiais poliméricos, foi realizado pela máquina WOLTEST MP3, seguindo a norma ASTM D 2240. O índice de fluidez foi determinado de acordo com a norma ASTM D 1238, $\left(190{ }^{\circ} \mathrm{C} / 2.160 \mathrm{~g}\right)$ utilizando as condições de medidas recomendadas para os polietilenos $\left(190{ }^{\circ} \mathrm{C} / 2.160 \mathrm{~g}\right)$. Para determinação do índice de fluidez foi utilizado um plastômero da marca DSM $\mathrm{MI}^{-1}$. A microscopia da Fibra de bananeira e dos compósitos PHB/Fibra de bananeira foi realizada através do Microscópio Eletrônico de Varredura da Marca JEOL JSM- 6510LV. As análises foram realizadas na fratura das amostras.

\section{RESULTADOS}

\subsection{Obtenção dos compósitos}

A Figura 3 mostra o PHB antes e após o processo de extrusão. É possível observar que houve uma alteração na colocação do material em comparação ao PHB antes do processamento. Esta coloração dourada castanha é proveniente da degradação térmica ocorrida no material.

Este escurecimento pode ser atribuído também a resíduos de bactérias ou de solventes oriundos do processo de extração do PHB [11]. No entanto, estudos indicam que mesmo o PHB purificado e com remoção total de solventes orgânicos apresenta escurecimento. Assim, sugere-se que tal degradação possa ser resultante de um processo termodegradativo do PHB, sendo a intensidade de escurecimento proporcional ao grau de degradação [3]. Alguns autores sugerem a utilização de catalisadores ou extensores de cadeia para minimizar a degradação térmica do PHB, ou ainda, a utilização de temperaturas mais amenas, evitando-se ultrapassar os $165^{\circ} \mathrm{C}$, por mais do que três minutos [12].

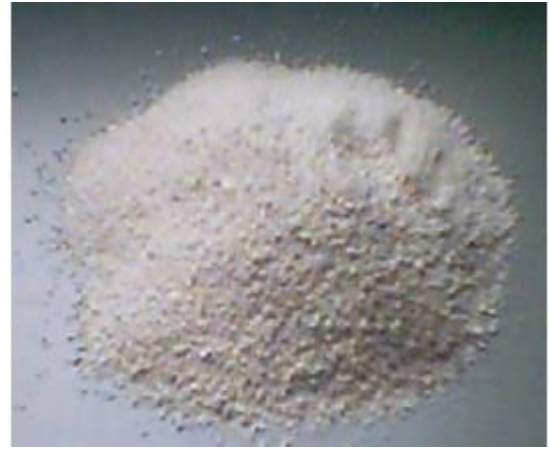

(a) PHB em pó

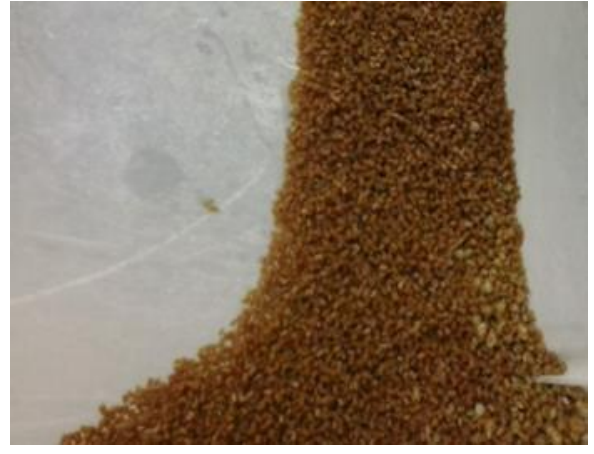

(b) PHB na forma de pellets

Figura 3: (a) PHB industrial não processado; (b) Pellets de PHB/FB extrudado.

\subsection{Caraterização térmica do material}

A variação da massa da amostra em função da programação de temperatura para o PHB comercial e o compósito $\mathrm{PHB} / \mathrm{FB}$, realizada através da análise termogravimétrica (TGA) pode ser observado na Figura 4.
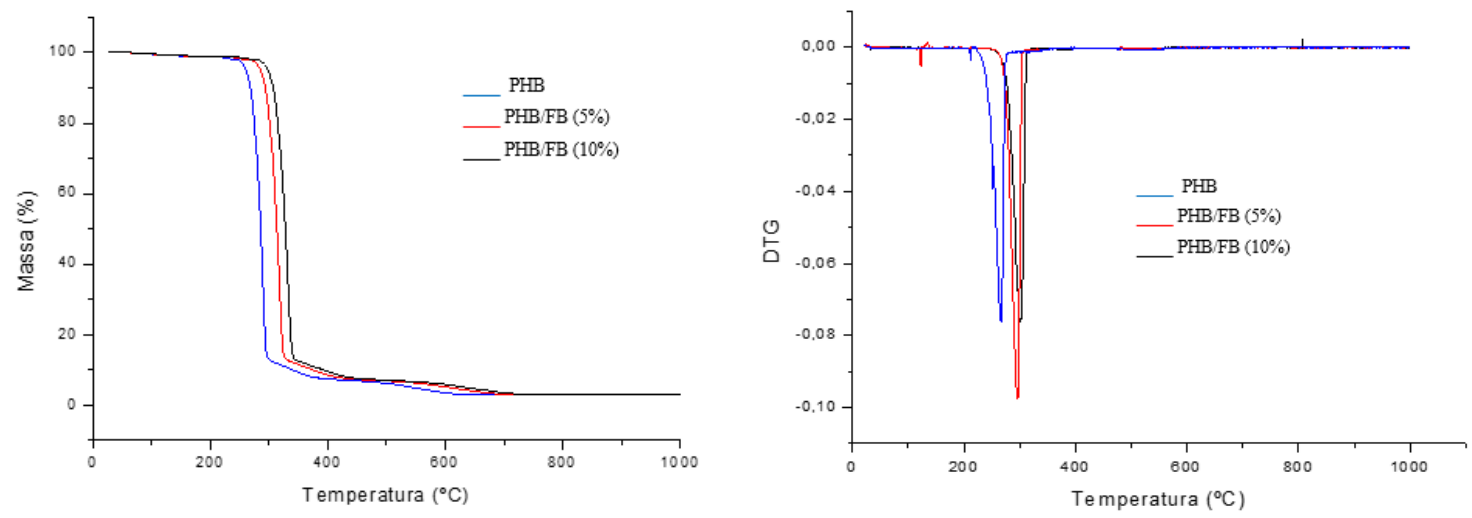

Figura 4: (a) Curvas de TGA e (b) DTG do PHB e dos compósitos PHB/FB. 
Observou-se que o PHB puro sofreu degradação térmica acima de $270{ }^{\circ} \mathrm{C}$, sendo o material totalmente decomposto em um único passo, com geração de 3,2\% de resíduo. A degradação térmica dos compósitos com 5 e $10 \%$ de fibra de bananeira ocorreu também em um único estágio, próximo a $300{ }^{\circ} \mathrm{C}$, permanecendo um resíduo de aproximadamente $1,8 \%$ da massa inicial da amostra. Observa-se um aumento da estabilidade térmica do material em aproximadamente $10 \%$ com a adição da fibra de bananeira. O grau de resíduo pode estar associado aos produtos/subprodutos utilizados nas etapas de extração/purificação do material.

HABLOT et al [2] mostraram resultados similares quando estudaram as características térmicas do PHB em sistemas multifaces. Encontraram valores de temperatura de degradação do PHB variando entre 280 - $300{ }^{\circ} \mathrm{C}$. MACEDO [12] apresentou o termograma e a derivada de perda de massa do PHB plastificado, onde são observadas duas etapas de perda de massa, entre $65-210^{\circ} \mathrm{C}$ e 250 - $376^{\circ} \mathrm{C}$. MACHADO [13] relatou temperatura de degradação térmica acima de $270{ }^{\circ} \mathrm{C}$ para o $\mathrm{PHB}$ puro, com total decomposição em um único passo até $360{ }^{\circ} \mathrm{C}$, sem geração de resíduo. Para o PHB com $30 \%$ de pó de madeira a degradação de $75 \%$ da massa da amostra ocorreu em um único estágio até $305^{\circ} \mathrm{C}$.

\subsection{Caracterização mecânica e característica de fluido}

O comportamento mecânico dos polímeros depende significativamente de algumas variáveis, a temperatura é uma das mais importantes. A Figura 5 mostra valores médios da curva Carga x Deslocamento obtida nos ensaios de flexão de três pontos das amostras dos compósitos e do PHB puro.

Observa-se que os materiais apresentaram comportamento rígido e frágil, caracterizado pela baixa deformação do material e sua repentina ruptura. Estas propriedades estão associadas à alta cristalização do PHB e dos compósitos. A fragilização do material pode ser prolongada durante certo tempo após a sua completa cristalização.

Devido à sua baixa taxa de nucleação, o PHB apresenta-se como um polímero diferenciado e tende a apresentar esferulitos relativamente grandes, com inúmeras fraturas inter-esferulíticas. A cristalização secundária consiste na formação de esferulitos originados a partir da reorganização das cadeias no estado amorfo em cristais lamelares pré- existentes $[9,14]$.

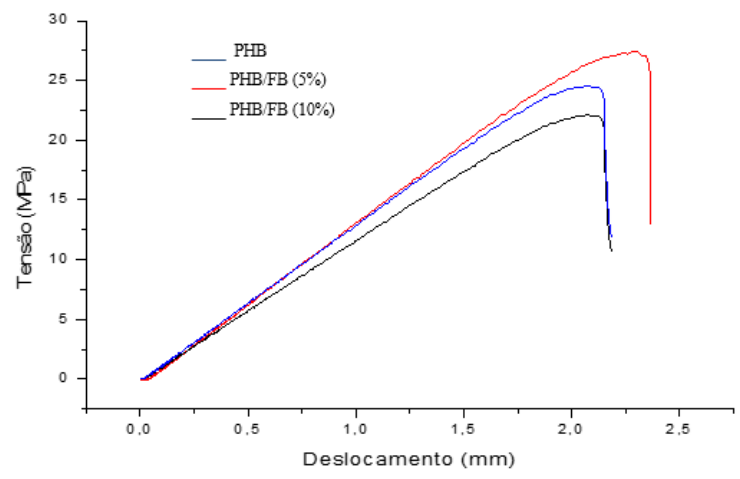

Figura 5: Curva Tensão (MPa) x Deslocamento (mm) das amostras de PHB e compósito PHB/FB

O processo de cristalização secundária (envelhecimento), que ocorre com a reorganização das cadeias na fase amorfa do biopolímero e se propaga durante a estocagem em temperatura ambiente, é observado no PHB em diversos estudos [15,16]. Os resultados obtidos para os ensaios mecânicos e de fluidez para as amostras produzidas estão apresentados na Tabela 1 . 
Tabela 1: Valores obtidos para os ensaios mecânicos e de fluidez para o PHB e para o biocompósito PHB/fibra de bananeira.

\begin{tabular}{|l|c|c|c|c|c|c|}
\cline { 2 - 7 } \multicolumn{1}{c|}{} & $\begin{array}{c}\text { Resistência a } \\
\text { Tração (MPa) }\end{array}$ & $\begin{array}{c}\text { Resistência a } \\
\text { Flexão (MPa) }\end{array}$ & $\begin{array}{c}\text { Módulo de } \\
\text { elasticidade } \\
\text { Flexão (MPa) }\end{array}$ & $\begin{array}{c}\text { Resistência a } \\
\text { impacto } \\
\left(\mathrm{KJ}_{\mathrm{N}}{ }^{2}\right)\end{array}$ & $\begin{array}{c}\text { Dureza (Shore } \\
\text { D) }\end{array}$ & $\begin{array}{c}\text { Índice fluidez } \\
\left(\mathrm{g} .10 \mathrm{~min}^{-1}\right)\end{array}$ \\
\hline PHB & $24,0 \pm 0,2$ & $28,4 \pm 0,2$ & 2655,25 & $8,34 \pm 0,2$ & $81,72 \pm 0,2$ & 33,0 \\
PHB/FB (5\%) & $26,5 \pm 0,6$ & $35,1 \pm 0,2$ & 2870,49 & $10,60 \pm 0,4$ & $79,32 \pm 0,2$ & 20,5 \\
PHB/FB (10\%) & $20,5 \pm 0,6$ & $30,4 \pm 0,2$ & 2450,20 & $9,40 \pm 0,2$ & $72,32 \pm 0,4$ & 14,4 \\
\hline
\end{tabular}

Os resultados de resistência à tração não apresentaram variação muito significativa com a introdução da carga de fibra de bananeira. O menor valor de tração foi obtido com $10 \%$ da fibra de bananeira, os resultados tiverem valores $24 \%$ menores que os resultados obtidos com o compósito com $5 \%$ da fibra de bananeira. Os valores de tensão para o biocompósito com 5\% de fibra foram mais próximo ao PHB puro, com um aumento da tensão de aproximadamente $10 \%$, desta forma, este compósito tornou-se um pouco mais resistente à ruptura em tração do que o material puro.

Sousa (2016) encontrou resultados de resistência a tração de 25 MPa para amostras de PHB/ curauá (80/20) em massa, e deformação de aproximadamente 3\% superior ao PHB puro. Azevedo et al (2013a) observaram redução das propriedades mecânicas do compósito PHB/casca de arroz com o aumento do percentual da fibra, que variou entre $15-45 \%$. A adição da fibra ocasionou materiais mais rígidos com redução da deformação na ruptura e maior fragilidade.

Em relação à deformação, a tendência natural é que seja diminuída com a o aumento das concentrações de fibra, visto que essa adição geralmente causa uma diminuição da ductilidade da matriz pela adição de um reforço mais cristalino [9]. Neste trabalho observa-se que os compósitos com 5\% de fibra apresentou aumento de $9 \%$ em relação à deformação do PHB puro, resultado contrário à citação de SOUSA [9]. O aumento do percentual da fibra para $10 \%$ causou redução do módulo de elasticidade, esta redução pode estar associada à falta de interação entre a matriz polimérica e a fibra de bananeira ou ainda a uma concentração de tensão localizada, oriunda da presença de regiões de falha.

Analisando-se os valores de resistência ao impacto para o PHB puro e os compósitos, verifica-se que essa propriedade teve um incremento de $27 \%$ com a adição de $5 \%$ de fibra de bananeira e de $12 \%$ com a adição de $10 \%$ de fibra. NETO (2011) obteve resultados similares ao analisar a resistência ao impacto em compósitos $\mathrm{PHB} /$ pó de madeira, compósitos com $10 \%$ de pó de madeira apresentaram valores maiores que compósitos com 30\%. Ambos apresentaram valores de impacto superiores ao PHB puro.

Para os resultados de dureza Shore obtidos, observou-se que os compósitos PHB/FB têm valores inferiores ao da dureza do PHB puro, apresentando uma redução mais expressiva quando há um aumento na concentração da fibra de bananeira para $10 \%$. Este fato pode estar associado à forma com que a fibra esta distribuída na matriz. Machado [13] em seus estudos com PHB e compósitos PHB/Fibra de madeira não encontrou variações significativas de dureza Shore associado ao percentual de fibra na matriz.

Observa-se que a literatura traz variações entre os resultados mecânicos dos biocompósitos, mesmo quando se utiliza a mesma fibra na matriz de PHB, esta variação pode estar associada à dificuldade de homogeneidade na mistura das amostras devido à dificuldade de interação com a matriz, ou ainda relacionada a características inerentes às fibras quanto a forma de extração, tratamento químico, e até época de colheita da fibra. Os resultados apresentados na Tabela 1 sugerem um melhor desenvolvimento do material, principalmente no que tange a interação da fibra-matriz e das variáveis do processamento, com intuito de padronização e obtenção de melhores resultados.

\subsection{Caracterização morfológica do material}

A análise morfológica do material complementa a caracterização mecânica e térmica. Através das imagens observa-se a disposição das fibras dentro da matriz poliméricas e a adesão das mesmas à matriz. Imagens da superfície de fratura do polihidroxibutirato e do biocompósito PHB/Fibra de Bananeira estão representadas nas Figura 6 e Figura 7, respectivamente. 


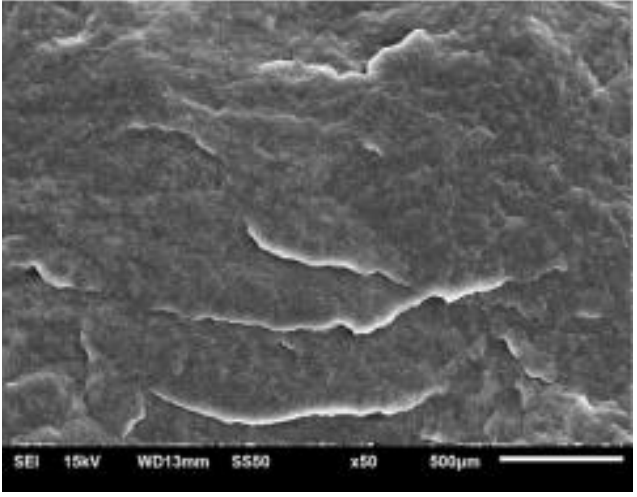

(a) Resolução 50x

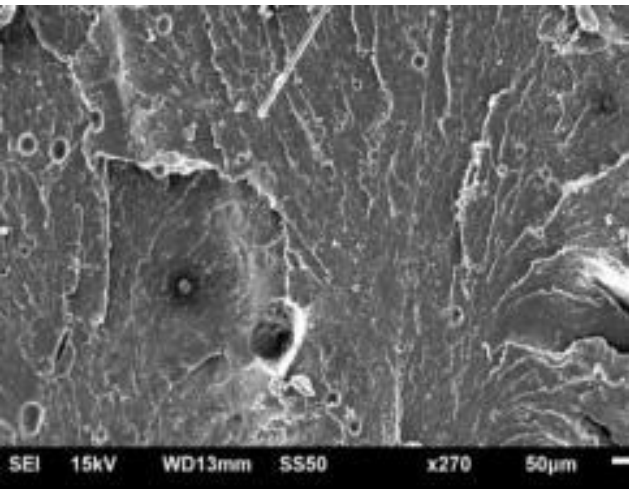

(b) Resolução 270x

Figura 6: Micrografia Eletrônica do PHB. Ampliações de 50x e 270x.

De acordo com as imagens realizadas na fratura das amostras, é possível observar que o PHB apresenta uma fase contínua e uma rugosidade na superfície da fratura, com características de superfície relativamente plana e brilhante, resultando numa topografia típica de fratura frágil, estando de acordo com os resultados dos ensaios mecânicos apresentados na Tabela 1 e nas imagens das curvas de Tração x Deformação, apresentados na Figura 5. Na ampliação 270x é possível observar a presença de microporos distribuídos ao longo da superfície, provenientes da evaporação de líquidos residuais presentes no material, eliminados durante o processo de moldagem. A presença das bolhas e microporos tornam-se prejudiciais ao desempenho mecânico do material, pois tornam-se um concentrador de tensões, podendo direcionar trincas e promover a ruptura precoce do material.

Na micrografia apresentada na Figura 7 foi possível observar uma fraca adesão fibra x matriz, associado ao caráter hidrofílico da celulose presente na fibra de bananeira. Esta característica afeta a dispersão das fibras, tendendo a formar aglomerados por interações moleculares do tipo pontes de hidrogênio. $\mathrm{O}$ aglomerado de fibras pode causar um inchamento do biocompósito devido ao aumento da absorção de umidade. Além da formação de aglomerados, foi possível observar a presença de espaços vazios provenientes do descolamento da fibra, não houve um rompimento da fibra proporcional ao rompimento da matriz, e sim um maior descolamento. Este fato pode ser associado também ao tamanho da fibra e sua descontinuidade. Estes fatores interferem nas propriedades de resistência mecânica do material.

Um dos principais objetivos da utilização de fibras naturais como reforço polimérico é a transferência dos esforços no carregamento da matriz para a fibra. Um dos resultados que pode ser esperando é que ocorra o rompimento da fibra e não o seu descolamento (Figura 7b), estas diferenças interferem no tipo de fratura do material.

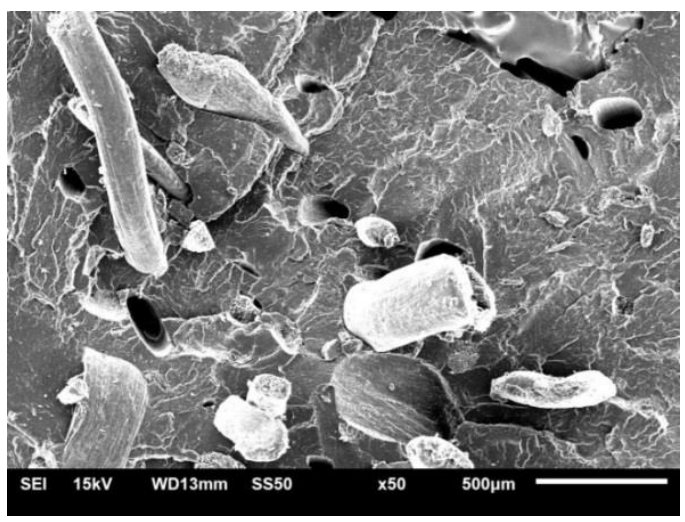

a) Resolução 50x

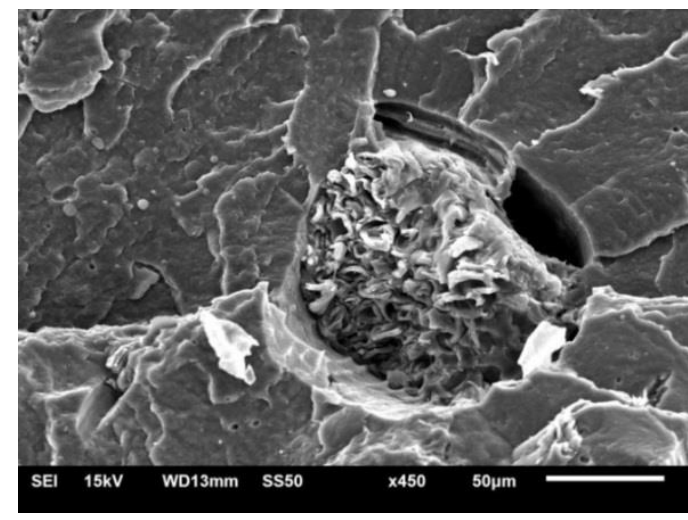

b) Resolução 450x

Figura 7: Microscopia Eletrônica do biocompósito PHB/fibra de bananeira (FB), resolução 50x, 450x 
MOURA [19] obteve micrografias similares às apresentadas neste trabalho quando avaliou a aderência do PHB à casca de arroz e fibras de coco. Classificou o compósito PHB / casca de arroz como de boa aderência e com a fibra de coco de aderência intermediária. Suas imagens mostram momentos de descolamento e de rompimento da fibra para ambos os materiais.

SOUZA [9] mostrou que as fibras de carauá tratadas quimicamente aderiram melhor à matriz do PHB em comparação as fibras in natura. Suas imagens demonstraram boa aderência e melhoramento das propriedades mecânicas do compósito obtido com fibras lavadas e mercerizadas.

\section{CONCLUSÕES}

Foi possível obter compósito $\mathrm{PHB} / \mathrm{FB}$ com $5 \%$ e $10 \%$ da fibra. O tratamento químico a base de $\mathrm{NaOH}$ proporciona aumento na rugosidade da fibra melhorando a ancoragem da fibra à matriz, observa-se nas micrografias uma fraca aderência. Observa-se que houve um leve acréscimo nas propriedades mecânicas nos compósitos produzidos com $5 \%$ da $\mathrm{FB}$, principalmente nas propriedades de resistência à tração e impacto. Com o aumento do percentual de fibra foi possível observar diminuição das propriedades mecânicas, no entanto valores ainda muito próximos da matriz pura. $\mathrm{O}$ estudo indica que a fibra de bananeira pode ser utilizada como reforço em PHB, reduzindo o custo do material com melhoria ou manutenção das propriedades mecânicas do PHB puro.

\section{AGRADECIMENTOS}

Ao Laboratório de caracterização de materiais do SENAI CIMATEC, ao grupo GCIM da UFBA.

\section{BIBLIOGRAFIA}

[1] CASARIN, S. A., AGNELli, J. A. M., MALMONGE, S. M., et al. "Blendas PHB copoliésteres biodegradáveis", Polímeros v. 23, pp. 115-122, 2013.

[2] HABLOT, E., BORDES, P., POLLET, E., et al., "Thermal and thermo-mechanical degradation of poly(3hydroxybutyrate)-based multiphase systems", Polymer Degradation and Stability, v. xx, p.p. 1-9, 2007.

[3] PACHEKOSKI, W. M. Desenvolvimento de blendas biodegradáveis constituídas de poli(hidroxibutirato) - PHB e poli(ácido lático) - PLA para a fabricação de filmes. Tese de D.Sc. UFSCar, São Carlos, SP, Brasil, 2005.

[4] SILVA, L. F., GOMEZ, J. G.C., ROCHA, R.C.S., et al., Produção biotecnológica de polihidroxialcanoatos para a geração de polímeros biodegradáveis no Brasil, Química Nova, v. 30, n. 7, p. 1732$1743,2007$.

[5] JESUS, R. C. Processamento e caracterização de biocompósitos de PHB com fibras naturais de coco e sisal acetiladas e não acetiladas. Feq/UNICAMP, Campinas, SP, Brasil, 2008.

[6] QUENTAL, A. C., CARVALHO, F.P., TADA, E.S., et al., "Blendas de PHB e seus copolímeros: miscibilidade e compatibilidade", Química Nova. v. 33, n. 2, pp. 438-446, 2010

[7] TĂNASE, E. E., POPA, M.E., RAPA, M., et al., "PHB/Cellulose fibers based materials: physical, mechanical and barrier properties", Agriculture and Agricultural Science Procedia , v. 6, pp. 608-615, 2015.

[8] MEDEIROS, E. S., MATTOSO, L. H. C., CARVALHO, L. H., et al., Uso de tecidos de fibras vegetais para melhoria das propriedades de materiais plásticos, In: Circular Técnica 16, EMBRAPA, São Carlos SP, 2002.

[9] SOUSA, V. M. Z. Caracterização mecânica, térmica e morfológica de compósitos de polihidroxibutirato (PHB) reforçados com fibras de curauá, Dissertação de M.Sc, FGA/FT/UnB, Brasília, DF, Brasil, 2016.

[10] BALZER, P. S., VICENTE, L.L., BRIESEMEISTER, R., et al., "Estudo das propriedades mecânicas de um composto de PVC modificado com fibras de bananeira", Polímeros: Ciência e Tecnologia v. 17, pp. 1-4, 2007.

[11] CAMARGO, F. A. Biodegradação de blendas de poli (3-hidroxibutirato- co-valerato)/(PHBV) com lignina de bagaço de cana de açúcar, Dissertação M.Sc., Feq/UNICAMP, Campinas, SP, Brasil, 2003. 
[12] MACEDO, J. S. Desenvolvimento de biocompósitos à base de polihidroxibutirato e resíduos do processamento de fibras de casca de coco, Tese de D.Sc., COPPE/UFRJ, Rio de Janeiro, RJ, Brasil, 2010.

[13] MACHADO, M.. L. C., PEREIRA, N.C., MIRANDA, L.F., et al., "Estudo das propriedades mecânicas e térmicas polímero biodegradável poli 3 hidroxibutirato e de compósitos PHB- pó de madeira", Polímeros v. 20, pp. 65-71, 2010.

[14] NASCIMENTO, J. F. Estudo da Processabilidade e da Caracterização do Poli (ácido 3- hidroxibutírico)- PHB Obtido a Partir de Cana- de-Açúcar, Dissertação de M.Sc, Feq/UNICAMP, Campinas, SP, Brasil 2001.

[15] BLAZEK, G. R. Estudo da blenda Poli (3-Hidroxibutirato)/Poli (Etileno Glicol), Tese D.Sc. Escola Politécnica/USP, São Paulo, SP, Brasil, 2018.

[16] KONING, G. J. M., LEMSTRA, P. J. "Crystallization phenomena in bacterial poly [(R)-3hydroxybutyrate]: Embrittlement and rejuvenation”, Polymer. v. 34, n. 19, 1993.

[17] AZEVEDO, J. B., et al., "Avaliação da concentração de casca de arroz nas propriedades mecânicas de compósitos com PHB”, In: $12^{\circ}$ Congresso Brasileiro de Polímeros $\left(12^{\circ} \mathrm{CBPol}\right)$ Florianópolis, SC, Brasil, 22 26 Setembro, 2013.

[18] NETO, T. A. Estudo de compósitos poliméricos biodegráveis de poli-hidroxibutirato (PHB), poli عcaprolactona $(P C L)$ e pó de madeira, Dissertação de M.Sc, faculdade de tecnologia SENAI CIMATEC, Salvador, BA, Brasi2011.

[19] MOURA, A. S. Estudo comparativo das propriedades mecânicas e térmicas entre compósitos de PHB (polihidroxibutirato) reforçados com casca de arroz ou fibra de coco, Tese de D.Sc., FGA/FT/UnB, Brasília, DF, Brasil. 2014. 